ORIGINAL ARTICLE

\title{
Correlations between physiological variables and performance in high level cross country off road cyclists
}

\author{
F M Impellizzeri, S M Marcora, E Rampinini, P Mognoni, A Sassi
}

Br J Sports Med 2005;39:747-751. doi: 10.1136/bjsm.2004.017236

See end of article for authors' affiliations

.....................

Correspondence to: Franco M Impellizzeri, Human Performance Laboratory, S S Mapei, Castellanza 21053, Italy; mapeisport@tin.it

Accepted 14 March 2005

\begin{abstract}
Objectives: To examine the relations between maximal and submaximal indices of aerobic fitness and off road cycling performance in a homogeneous group of high level mountain bikers.

Methods: 12 internationally competitive mountain bikers completed the study. Maximum oxygen uptake $\left(\dot{V}_{2 \text { max }}\right)$, peak power output (PPO), power output (PO), and oxygen uptake $\left(\dot{V}_{2}\right)$ at first (VT) and second $(R C T)$ ventilatory thresholds were measured in the laboratory, and correlated with race time during a cross country circuit race.

Results: The only physiological indices of aerobic fitness correlated with off road cycling performance were $\mathrm{PO}$ and $\dot{\mathrm{V}}_{2}$ at RCT when normalised to body mass ( $r=-0.63$ and $r=-0.66$, respectively; $\mathrm{p}<0.05$ ). VT, $\dot{V} \mathrm{O}_{2 \mathrm{max}}$, and PPO were not correlated to performance in this homogeneous group of high level mountain bikers.

Conclusions: The results of this study suggest that submaximal indices of aerobic fitness such as PO and $\dot{V}_{2}$ at RCT are more important determinants of off road cycling performance than maximal indices such as PPO and $\dot{V}_{2 \max }$. This study confirms the importance of body mass for mountain biking performance. As aerobic fitness explained only $40 \%$ of the variance, other physiological and technical factors should be investigated, as they may be important determinants of cross country performance among elite mountain bikers.
\end{abstract}

M ountain biking is a popular recreational and competitive sport, and one of its most popular events (cross country circuit racing) was included as an official Olympic sport in the 1996 Atlanta Summer Games. Despite the growing interest in it, few studies have investigated the physiological aspects of this sport. ${ }^{1-6}$ Overall, the available studies show that cross country circuit races are carried out at very high exercise intensity, with average competition heart rate close to $90 \%$ of maximum for races lasting up to two hours, ${ }^{12}$ and with power output (PO) values reaching 250 to $500 \mathrm{~W}$ during uphill cycling. ${ }^{2}$ Furthermore, more recent investigation has shown that high maximum oxygen uptake $\left(\dot{V}_{2 \max }\right)$ and the capacity to maintain high submaximal aerobic work (lactate thresholds) are important determinants of off road performance. ${ }^{6}$ Some studies have also demonstrated that body mass should be taken into account when evaluating the physiological characteristics of mountain bikers and their relation to off road cycling performance. ${ }^{4} 6$

To date, the relations between physiological indices of aerobic fitness and performance have been investigated only in a heterogeneous group of off road cyclists with large race time differences between the first and last cyclists within the group (26 minutes). ${ }^{6}$ However, when applied to more homogeneous samples, some physiological variables were found to be poor discriminators of performance differences. ${ }^{7}$ In fact, previous studies in road cycling suggest that some physiological predictors of time trial performance in a group of cyclists of different performance levels ${ }^{8-11}$ might not be associated with performance in a more homogeneous group of top level professional cyclists. ${ }^{12}$

The aim of this study was therefore to examine whether physiological indices of aerobic fitness similar to those found to be correlated with cross country race performance in a heterogeneous group of mountain bikers by Impellizzeri et $a l^{6}$ are also associated with performance in a more homogeneous group of elite off road cyclists (race time difference of six minutes).

\section{METHODS Subjects}

Fifteen male high level off road cyclists were recruited for the study (mean (SD) age 25.5 (3.8) years, height $175.9(6.4) \mathrm{cm}$, body mass $66.2(5.4) \mathrm{kg}$, maximum oxygen uptake $\left(\dot{\mathrm{V}}_{2 \max }\right)$ 75.9 (5.3) ml/kg/min, peak power output (PPO) 428 (39) W, off road cycling experience 9.9 (2.9) years). These mountain bikers were internationally competitive cyclists and eight of them had been classified at least once in the first 10 positions of the most important international competitions (World Cup, European Cup, World Championship, or Olympic Games). The other seven mountain bikers won several international events included in the UCI calendar. After being informed of the aims and procedures of the study and prior to commencement of testing, all subjects gave their written consent in accordance with the Declaration of Helsinki. The study was approved by the institutional review board.

\section{Laboratory tests}

During the tapering week before a cross country competition, cyclists carried out an incremental maximal exercise test on an electromagnetically braked ergometer (SRM Ergometer, Welldorf, Germany) equipped with an SRM Powermeter incorporating 20 strain gauges (SRM Science, Welldorf, Germany). The ergometer were regularly checked for accuracy and reliability using a calibration rig (model 17810, Vacumed, Ventura, California, USA). The ergometer settings were individually adjusted to allow each cyclist to replicate the position he assumes on his own bicycle.

Subjects were instructed not to eat for at least three hours before testing, not to drink coffee or beverages containing

Abbreviations: $\mathrm{HR}_{\max }$ maximum heart rate; $\mathrm{PO}$, power output; $\mathrm{PPO}$, peak power output; $\mathrm{RCT}$, respiratory compensation threshold; $\mathrm{V}_{2}$, oxygen uptake; $\mathrm{V}_{2 \text { max }}$, maximum oxygen uptake; $\mathrm{VT}$, ventilatory threshold 
caffeine for at least eight hours before testing, and to avoid intense exercise for 48 hours before testing. The test started at $100 \mathrm{~W}$ and resistance increased by $25 \mathrm{~W} / \mathrm{min}$ until volitional exhaustion. The subjects were instructed to maintain a cadence between 90 and $95 \mathrm{rev} / \mathrm{min}$ throughout the test. The choice of this arbitrary cadence was based on our previous experience with mountain bikers, who prefer a high rather than a low cadence. This is in agreement with the results of Takaishi et al, ${ }^{13}$ who showed that well trained cyclists prefer a higher pedalling rate to minimise neuromuscular fatigue. Furthermore, in previous investigations on off road cyclists, a similar cadence range (90-100 rpm) was used. ${ }^{136}$ During the test, athletes were encouraged verbally by the laboratory technicians as well as by their team coach.

If the last workload was not completed, the PPO was calculated using the formula of Kuipers et al: ${ }^{14}$

$$
\mathrm{PPO}=\mathrm{W}_{\mathrm{f}}+(t / 60.25)
$$

Where $\mathrm{W}_{\mathrm{f}}$ is the last completed workload in watts, $t$ is the time in seconds of the uncompleted step, and 25 is the difference in watts between consecutive workloads.

Maximum oxygen uptake was measured using a breath by breath automated gas analysis system (VMAX29, Sensormedics, Yorba Linda, California, USA). Before each test, flow and volume were calibrated using a three litre capacity syringe (Sensormedics), while gas analysers were calibrated using two tanks of known concentrations of oxygen uptake $\left(\mathrm{O}_{2}\right)$ and carbon dioxide $\left(\mathrm{CO}_{2}\right)\left(16 \% \mathrm{O}_{2}\right.$ and $4 \% \mathrm{CO}_{2}, 26 \% \mathrm{O}_{2}$ and $0 \% \mathrm{CO}_{2}$, respectively; Sensormedics). Achievement of $\dot{\mathrm{V}}_{2 \max }$ was assumed on attainment of at least two of the following three criteria: a plateau in $\dot{\mathrm{V}}_{2}$ with increasing speeds; a respiratory exchange ratio above 1.10; a heart rate within \pm 10 beats/min of age predicted maximum heart rate $(220$-age $) .{ }^{15}$

Ventilatory threshold (VT) and respiratory compensation threshold (RCT) were assessed by combining three common methods for the determination of gas exchange thresholds according to Gaskill et al: ${ }^{16}$ ( 1 ) the ventilatory equivalent of $\mathrm{O}_{2}$ and $\mathrm{CO}_{2}\left(\dot{\mathrm{Ve}} / \dot{\mathrm{V}}_{2}\right.$ and $\dot{\mathrm{V} e} / \dot{\mathrm{V}} \mathrm{CO}_{2}$, respectively); (2) excess $\mathrm{CO}_{2}$; (3) the V-slope method. Thus, VT was visually detected as the intensity corresponding to (1) an increase in $\dot{\mathrm{V} e} / \dot{\mathrm{V}}_{2}$ with no increase in $\dot{\mathrm{V} e} / \dot{\mathrm{V}}_{\mathrm{CO}},(2)$ the first sustained rise in excess $\mathrm{CO}_{2}$, and (3) the first increase in the slope of the $\dot{\mathrm{V}}_{\mathrm{CO}_{2}} v \dot{\mathrm{V}}_{2}$ plot. RCT was determined as the intensity corresponding to (1) an increase in both $\dot{\mathrm{V} e} / \dot{\mathrm{V}} \mathrm{O}_{2}$ and $\dot{\mathrm{Ve}} / \dot{\mathrm{V}} \mathrm{CO}_{2} ;$ (2) the second sustained rise in excess $\mathrm{CO}_{2}$; and (3) the second increase in the slope of the $\dot{\mathrm{V}}_{2} v \dot{\mathrm{V}}_{2}$ plot. VT and RCT were detected by two independent experienced investigators. If the $\dot{\mathrm{V}}_{2}$ at VT and RCT determined by the two investigators was within 3\%, the mean value of the two investigators was used. When the difference exceed $3 \%$ a third investigator was asked to determine VT and RCT. The combination of these three methods of gas exchange threshold detection has been shown to improve the accuracy and reliability of VT identification. ${ }^{16}$

\section{Cross country competition}

The cross country circuit competition of international level was run in March (six laps, total distance of $33.6 \mathrm{~km}$ and total altitude climbed $1362 \mathrm{~m}$; data supplied by the race organisation). The day before the race, the participants were allowed to practise the competition course cycling at an intensity $<85 \%$ of maximum heart rate $\left(\mathrm{HR}_{\max }\right)$. Before the race, they carried out a warm up for one hour at intensities of $<80 \%$ of $\mathrm{HR}_{\max }$ and high cadence $(>90 \mathrm{rev} / \mathrm{min}$ ) on the road or using a cyclo-simulator. All athletes started the race with $500 \mathrm{ml}$ of an electrolyte solution and they were free to take a $500 \mathrm{ml}$ bottle of carbohydrate-electrolyte beverage or a maltodextrin gel $(30 \mathrm{ml})$ or both at each lap. Time taken to complete the race was used as the performance index (individual competition times were supplied by the race organisation). Athletes were instructed to complete the race in the fastest possible time. Only mountain bikers who completed the competition without mechanical problems were included. We used actual race performance as the dependent variable to examine the influence of the selected physiological predictors on real cross country performance and thus to increase the ecological validity of this study. However, the use of a single race performance has the limitation that correlations could be influence by the degree of technical ability required by the specific race course.

\section{Statistical analysis}

Data are reported as means (SD). Before using parametric tests, the assumption of normality was verified using the Shapiro-Wilk W test. Pearson's product-moment correlations were used to examine the relations between the aerobic fitness indices (expressed in absolute terms and normalised by body mass values) as measured during the laboratory tests $\left(\dot{\mathrm{V}}_{2 \max }, \mathrm{PPO}, \mathrm{PO}\right.$, and $\dot{\mathrm{V}}_{2}$ at VT and RCT), and time taken to complete the race. In off road cycling, a particular factor that could influence final race time is the starting position. The cross country discipline is a massed start event and the starting grid is defined according to the UCI points or the national points system, or both, for the national events. This allows the best cyclists to start in front of the group to avoid being slowed down by lower standard riders. A different starting position could influenced competition time and, consequently, its relation to laboratory variables. For this reason, in a previous similar study, Impellizzeri et $a l^{6}$ also applied the Spearman's rank correlation. In the present study, all the athletes started in the first two lines and so their starting positions could not have influenced the correlations. The level of statistical significance was set at $\mathrm{p}<0.05$. Statistical analyses were undertaken using the

Table 1 Characteristics of off road cyclists who completed the race and were included in the final statistical analysis $(n=12)$

\begin{tabular}{|c|c|c|c|}
\hline & Mean (SD) & Min & Max \\
\hline Age (years) & $24.9(2.9)$ & 23.0 & 32.0 \\
\hline Weight (kg) & $66.4(5.7)$ & 54.0 & 75.0 \\
\hline Height $(\mathrm{cm})$ & $176(7)$ & 165.0 & 188.0 \\
\hline$\dot{\mathrm{V}} \mathrm{O}_{2 \max }$ (litres/min) & $5.11(0.46)$ & 4.58 & 6.11 \\
\hline$\dot{\mathrm{V}} \mathrm{O}_{2 \max }(\mathrm{ml} / \mathrm{kg} / \mathrm{min})$ & $76.9(5.3)$ & 70.8 & 86.1 \\
\hline $\mathrm{V}_{2 \max }\left(\mathrm{ml} / \mathrm{kg}^{0.79} / \mathrm{min}\right)$ & $185.8(11.7)$ & 170.0 & 210.7 \\
\hline VO $\mathrm{O}_{2 R C T}$ (litres/min) & $4.45(0.36)$ & 4.01 & 5.32 \\
\hline$\dot{\mathrm{V}} \mathrm{O}_{2 \mathrm{RCT}}(\mathrm{ml} / \mathrm{kg} / \mathrm{min})$ & $67.3(4.8)$ & 61.0 & 75.0 \\
\hline$\dot{V} \mathrm{O}_{2 \mathrm{RCT}}\left(\mathrm{ml} / \mathrm{kg}^{0.79} / \mathrm{min}\right)$ & $162.1(10.4)$ & 149.8 & 183.5 \\
\hline$\dot{\mathrm{V}} \mathrm{O}_{2 \mathrm{VT}}$ (litres/min) & $3.77(0.43)$ & 3.15 & 4.79 \\
\hline$\dot{\mathrm{V}} \mathrm{O}_{2 \mathrm{TT}}(\mathrm{ml} / \mathrm{kg} / \mathrm{min})$ & $56.8(4.8)$ & 50.8 & 67.5 \\
\hline$\dot{\mathrm{V}} \mathrm{O}_{2 \mathrm{VT}}\left(\mathrm{ml} / \mathrm{kg}^{0.79} / \mathrm{min}\right)$ & $137.0(11.5)$ & 121 & 165 \\
\hline $\mathrm{PPO}(\mathrm{W})$ & $426(40)$ & 373 & 525 \\
\hline $\mathrm{PPO}(\mathrm{W} / \mathrm{kg})$ & $6.4(0.6)$ & 5.8 & 7.4 \\
\hline $\mathrm{PPO}\left(\mathrm{W} / \mathrm{kg}^{0.79}\right)$ & $15.5(1.2)$ & 14.0 & 18.1 \\
\hline $\mathrm{PO}_{\mathrm{RCT}}(\mathrm{W})$ & $360(29)$ & 323 & 432 \\
\hline $\mathrm{PO}_{\mathrm{RCT}}(\mathrm{W} / \mathrm{kg})$ & $5.4(0.4)$ & 4.9 & 6.1 \\
\hline $\mathrm{PO}_{\mathrm{RCT}}\left(\mathrm{W} / \mathrm{kg}^{0.79}\right)$ & $13.1(0.9)$ & 12.0 & 14.9 \\
\hline $\mathrm{PO}_{V T}(\mathrm{~W})$ & $272(40)$ & 230 & 365 \\
\hline $\mathrm{PO}_{V T}(\mathrm{~W} / \mathrm{kg})$ & $4.1(0.6)$ & 3.3 & 5.2 \\
\hline$P_{V T}\left(\mathrm{~W} / \mathrm{kg}^{0.79}\right)$ & $9.9(1.4)$ & 8.1 & 12.6 \\
\hline Maximum HR (beats/min) & $183(8)$ & 171 & 201 \\
\hline $\mathrm{HR}_{\mathrm{RCT}}$ (beats/min) & $168(7)$ & 155 & 180 \\
\hline $\mathrm{HR}_{V T}$ (beats/min) & 148 (10) & 132 & 162 \\
\hline$\dot{V}$ e $\max$ (litres/min) & 179 (12) & 160 & 197 \\
\hline Race time $(\mathrm{s})$ & $6826(101)$ & 6650 & 6995 \\
\hline
\end{tabular}

HR, heart rate; PO, power output; PPO, peak power output; RCT, respiratory compensation point; $\dot{V}_{e}$, ventilation; $\dot{V}_{2 m a x}$, maximum oxygen uptake, VT, ventilatory threshold. 


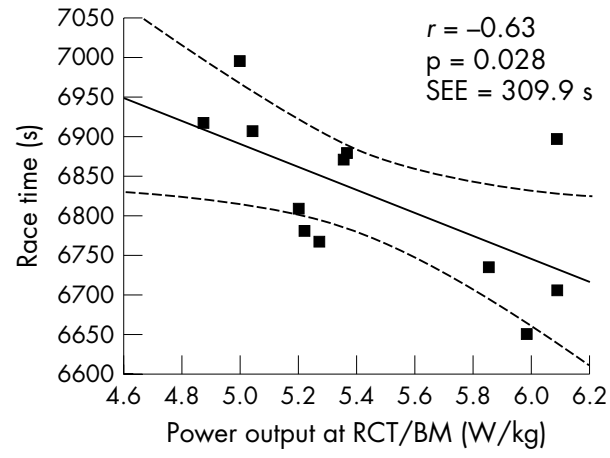

Figure 1 Scatterplot of race time $v$ power output at respiratory compensation threshold (RCT), normalised to body mass (BM) raised to the power of 1 . SEE, standard error of estimate.

software package STATISTICA (version 6.0, StatSoft, Tulsa, Oklahoma, USA).

\section{RESULTS}

Three off road cyclists withdrew from the race owing to mechanical problems. Thus only 12 mountain bikers were included in the final analysis. The characteristics of these subjects are presented in table 1.

Correlation between race time and $\dot{\mathrm{V}}_{2 \text { max }}, \mathrm{PPO}, \mathrm{PO}$, and $\dot{\mathrm{V}}_{2}$ at RCT and VT, expressed in absolute values and normalised by body mass and relative confidence intervals (CI 95\%), are presented in table 2 . $\dot{\mathrm{V}}_{2}$ and PO corresponding to RCT normalised to body mass raised to the power of 1 and 0.79 were found to be moderately correlated with race time (figs 1, 2, 3, and 4).

\section{DISCUSSION}

The main finding of this study was that $\dot{\mathrm{V}}_{2 \max }$ and PPO were not correlated with cross country circuit race performance, and that the only predictors of off road cycling performance were $\mathrm{PO}$ and $\dot{\mathrm{V}}_{2}$ at RCT normalised to body mass raised to the power of 1 and 0.79 . This is in contrast with our previous findings in a less homogeneous group of off road cyclists, in which $\dot{\mathrm{V}}_{2 \max }, \mathrm{PPO}$, and lactate thresholds were all highly correlated with performance in a cross country circuit race. On the other hand, the results of the present study are similar to those recently reported by Lucia et $a l^{12}$ who found that among a group of top professional road cyclists during the Tour de France, PO at VT was the only variable strongly correlated with time trial performance. While in the study of Impellizzeri et $a l^{6}$ maximal and submaximal indices of aerobic

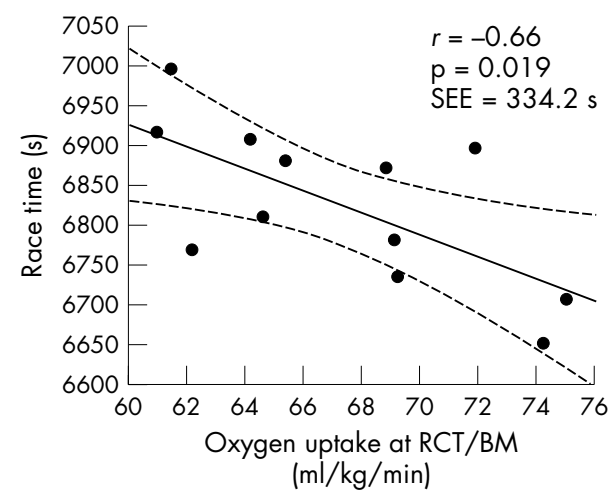

Figure 2 Scatterplot of race time $v$ oxygen uptake at respiratory compensation threshold (RCT), normalised to body mass (BM). SEE, standard error of estimate.

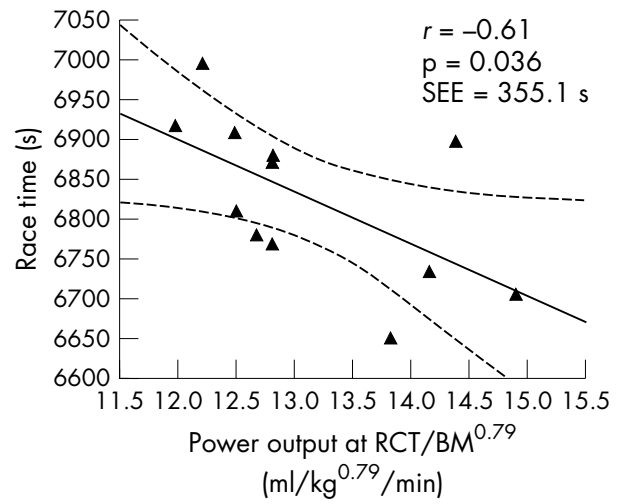

Figure 3 Scatterplot of race time $v$ power output at respiratory compensation threshold (RCT), normalised to body mass (BM) raised to the power of 0.79 . SEE, standard error of estimate.

fitness explained $80 \%$ of the variance in off road performance, in the present study the only variables found to be correlated with cross country circuit race performance (intensity at RCT) explained about $40 \%$ of variance. This confirms that the physiological predictors of performance in a heterogeneous group of athletes cannot be applied to high level athletes who are characterised by a more homogeneous performance ability. ${ }^{7}$ The greater heterogeneity of the sample used by Impellizzeri et $a l^{6}$ is shown by the difference between the race time of the first and the last riders within the group investigated ( $\sim 26$ minutes), while in the present study this was only six minutes.

The intensity at RCT found in the present study for elite off road cyclists $\left(91.8 \%\right.$ of $\mathrm{HR}_{\max }$ and $87.5 \%$ of $\dot{\mathrm{V}}_{2 \max }$ ) is similar to that reported for top level professional road cyclists. ${ }^{17} 18$ According to Lucia et al ${ }^{17}$ the high RCT intensity could reflect the ability to tolerate high exercise intensity during cycling competitions. Indeed, the RCT intensity found in our group of off road cyclists is similar to the relative heart rate and estimated $\dot{\mathrm{V}}_{2}$ reported for cross country off road cycling races $^{126}\left(91 \%\right.$ of $\mathrm{HR}_{\max }$ and $84 \%$ of $\left.\dot{\mathrm{V}}_{2 \max }\right)$. It is possible that the factors influencing the respiratory $\mathrm{pH}$ defence against lactic acid reflected by RCT (chemoreflex feedback provided by $\mathrm{PCO}_{2}$, hydrogen ion, potassium, catecholamines, and increased body temperature $)^{19}$ are important during off road competitions which are characterised by high exercise intensity in which anaerobic energy production probably plays a significant role. As intense exercises cause the production of large amounts of lactic acid, leading to an

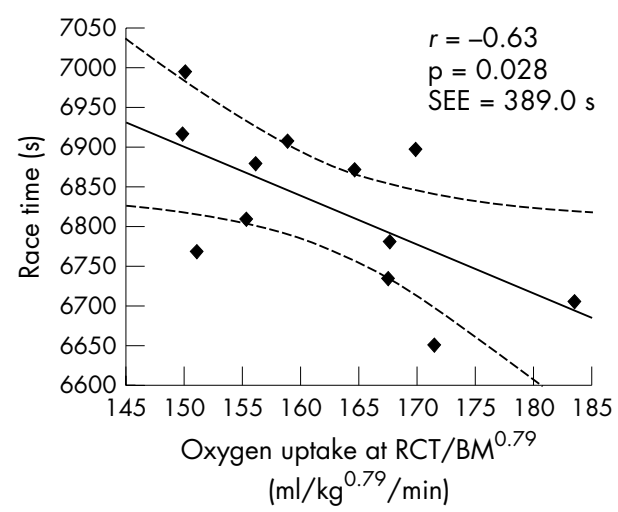

Figure 4 Scatterplot of race time $v$ oxygen uptake at respiratory compensation threshold (RCT), normalised to body mass (BM) raised to the power of 0.79 . SEE, standard error of estimate. 
Table 2 Correlations (Pearson $r$ ) between race time and physiological variables expressed as absolutes and scaled to body mass values $(n=12)$

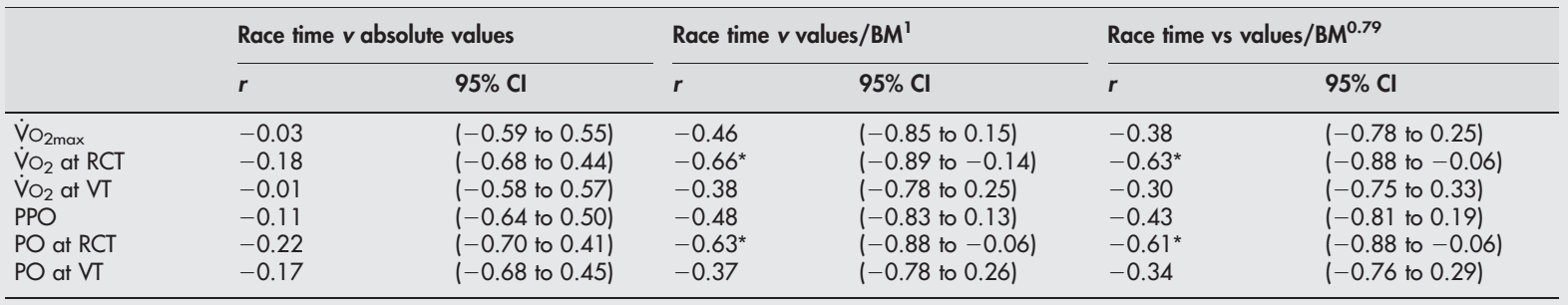

$\mathrm{BM}$, body mass; $\mathrm{Cl}$, confidence interval; $\mathrm{PO}$, power output; $\mathrm{PPO}$, peak power output; $\mathrm{RCT}$, respiratory compensation point; $\dot{\mathrm{V}}_{2 \mathrm{max}}$ maximum oxygen uptake, $\mathrm{VT}$, ventilatory threshold.

${ }^{*} \mathrm{p}<0.05$.

increase in hydrogen ion activity, the hyperventilation response acts as a rapid way of maintaining pH stability. ${ }^{20}{ }^{21}$ The importance of the aerobic-anaerobic transition (that is, lactate thresholds and VTs) at a high workload, other than a high $\dot{\mathrm{V}}_{2 \text { max }}$, has also been suggested and reported for cross country skiing competitions which are usually performed at exercise intensities of between $85 \%$ and $90 \%$ of $\dot{\mathrm{V}}_{\mathrm{O}_{2 \max },{ }^{22}}{ }^{23}$ similar to off road cycling races.

Like Impellizzeri et al, ${ }^{6}$ we found that body mass should be taken into account when investigating the physiological determinants of off road cycling performance. In fact, PO and $\dot{\mathrm{V}} \mathrm{O}_{2}$ at RCT were significantly associated with cross country circuit race performance only when normalised to body mass. In the study by Impellizzeri et $a l^{6}{ }^{6}$ the best correlations $(r>0.90)$ between a cross country race and $\dot{\mathrm{VO}}_{2 \text { max }}, \mathrm{PPO}$, and $\mathrm{PO}$ at lactate threshold were found when these variables were normalised to body mass. This further confirms the conclusions of Lee et al ${ }^{4}$ that power to weight characteristics are important for success in off road events. Lee et al compared top level Australian mountain bikers and professional road cyclists and found no significant differences between groups in $\dot{\mathrm{V}}_{{ }_{2 p e a k}}, \mathrm{PPO}$, lactate threshold, or average power output during a 30 minute laboratory time trial, expressed in absolute values. However, when these physiological variables were scaled to body mass, significantly higher values were found in off road cyclists compared with road cyclists. Moreover, Lee $e t \mathrm{l}^{4}$ reported that the off road cycling world champions from 1997 to 2000 had an average body weight of about $60 \mathrm{~kg}$, a value similar to that reported in high level climber road cyclists. ${ }^{17}{ }^{24}$ The body mass found in the present investigation and in Lee's study are only slightly higher than the 64.3 and $62.4 \mathrm{~kg}$ reported, respectively, by Lucia et al $^{17}$ and Padilla et $a^{24}$ for climbers.

The average $\dot{\mathrm{V}}_{2 \max }$ measured in the off road cyclists involved in the present study are similar to those reported by Lee et al for Australian elite mountain bikers, ${ }^{4}$ and to the $\dot{\mathrm{V}}_{2 \max }$ measured by Lucia et al $(78.6 \mathrm{ml} / \mathrm{kg} / \mathrm{min})^{17}$ and estimated by Padilla et al $(80.9 \mathrm{ml} / \mathrm{kg} / \mathrm{min})^{24}$ for top level climber road cyclists. Overall, the mountain bikers' physiological characteristics given in previous reports and in the present investigation (table 3 ) indicated that a high $\dot{\mathrm{V}}_{2 \max }$ $(>70 \mathrm{ml} / \mathrm{kg} / \mathrm{min})$ is a prerequisite for competing at high level in off road events.

The unexplained $60 \%$ of variance in off road cycling performance found in the present study could be related to other physiological or technical factors. Cross country circuit races are undertaken at very high exercise intensity ${ }^{12}$ with peak PO, directly measured using mobile crank dynamometers, ranging between 250 to $500 \mathrm{~W}$ during uphill cycling. ${ }^{2}$ Owing to the high PO required during steep climbing at the start of the race and when sprinting to pass slower riders, several investigators ${ }^{125}$ have suggested that high anaerobic power or capacity, or both, rather than high aerobic fitness, are important for meeting the physiological demands of off road cycling competitions. Baron ${ }^{5}$ compared maximal aerobic and anaerobic power of a group of elite mountain bikers with sport science students. He showed that national and international level off road cyclists have higher $\dot{\mathrm{V}}_{\mathrm{O}_{2} \max }$, PPO, and PO at the $4 \mathrm{mmol} / \mathrm{l}$ fixed lactate threshold compared with sport science students, and they also showed higher anaerobic power measured during 10 second isokinetic cycling tests at cadence ranging from 50 to $140 \mathrm{rev} /$ min. According to Baron, anaerobic characteristics should routinely be evaluated in cyclists in addition to physiological indices of aerobic fitness. As factors such as anaerobic power and non-respiratory buffering capacity (bicarbonate and nonbicarbonate) could account for part of the unexplained variance of the present study, further studies are necessary to investigate the contribution of anaerobic energy system to off road performance. Moreover, the ability to recover during the descents following the several climbs should be also investigated because it could account for an important portion of the unexplained variance.

Another determinant of off road performance could be technical ability. Off road competitions are characterised by repeated climbs and descents. While prowess at hill climbing requires a high power to weight ratio for top performance, descents carried out over different terrain conditions (dirt and gravel roads) necessitate a high degree of technical ability. Thus it is possible that among a homogeneous group

Table 3 Maximum oxygen uptake $\left(\dot{V}_{2 \text { max }}\right)$ of off road cyclists in published reports

\begin{tabular}{|c|c|c|c|c|c|}
\hline Study & Cycling level & $\mathbf{n}$ & Height $(\mathrm{cm})$ & Mass (kg) & $\begin{array}{l}\dot{\mathrm{V}} \mathrm{O}_{2 \max } \\
(\mathrm{ml} / \mathrm{kg} / \mathrm{min})\end{array}$ \\
\hline Wilber et al (1997) ${ }^{3}$ & Int & 10 male & $176(7)$ & $72(8)$ & $70.0(3.7)$ \\
\hline Baron $(2001)^{5}$ & NAT and INT & 25 male & $1795)$ & $69(7)$ & $68.4(3.8)$ \\
\hline Lee et al $(2002)^{4}$ & Int & 7 male & $178(7)$ & 65 (7) & $78.3(4.4)$ \\
\hline Impellizzeri et al (2002) & Int & 5 male & $175(3)$ & $64(5)$ & $75.9(5.0)$ \\
\hline Stapelfeldt et al (2004) & & 9 male & $180(6)$ & $69(5)$ & $66.5(2.6)$ \\
\hline Impellizzeri et al $(2005)^{6}$ & NAT and INT & 13 male & 177 (8) & $65(6)$ & $72.1(7.4)$ \\
\hline Present study & $\operatorname{lnt}$ & 15 male & $176(7)$ & $66(6)$ & $75.9(5.3)$ \\
\hline
\end{tabular}

Int, international level off road cyclists; Nat, national level off-road cyclists; $\dot{V}_{2 \text { max }}$, maximum oxygen uptake. 


\section{What is already known}

A previous study conducted on a heterogeneous group of mountain bikers showed high correlations between maximal and submaximal indices of aerobic fitness $\left(\mathrm{V}_{2 \max }, \mathrm{PPO}\right.$, and lactate thresholds normalised to BM) and a cross country race. About $80 \%$ of variance in performance was explained by aerobic fitness.

\section{What this study adds}

In a homogeneous group of elite off road cyclists with high $\mathrm{V}_{2 \text { max }}$, the ability to sustain high intensity submaximal aerobic work (RCT/BM) was the only variable correlated with cross country performance. As only $40 \%$ of variance was explained, other physiological or technical factors may be important for elite performance in cross country events.

of high level off road cyclists technical ability may play a more important role than in a heterogeneous group of mountain bikers.

In conclusion, our results suggest that $\mathrm{PO}$ and $\dot{\mathrm{V}}_{2}$ at RCT are more important determinants of off road cycling performance than $\dot{\mathrm{V}}_{2 \max }$ and PPO in high level off road cyclists. As a result, training strategies in elite mountain bikers with high $\dot{\mathrm{V}}_{2}$ should focus on improving the capacity to maintain a high level of submaximal aerobic work (that is, RCT intensity). However, as significant correlation does not imply causality, ${ }^{7}$ experimental studies are needed to determine whether training aimed at improving lactate thresholds or VTs results in enhanced off road cycling performance. ${ }^{25}$ Furthermore, as the correlations we found explained only $40 \%$ of the variance in cross country performance, further studies should also investigate other technical and physiological factors associated with off road cycling performance in high level mountain bikers, using not only actual race performance but also laboratory race simulations.

\section{Authors' affiliations}

F M Impellizzeri, E Rampinini, A Sassi, Human Performance Laboratory, S S Mapei, Castellanza, Italy

S M Marcora, School of Sport, Health, and Exercise Sciences, University of Wales-Bangor, Bangor, UK

P Mognoni, National Research Council, Institute of Molecular Bioimaging and Physiology, Segrate, Milan, Italy
Competing interests: none declared

\section{REFERENCES}

1 Impellizzeri F, Sassi A, Rodriguez-Alonso $M$, et al. Exercise intensity during off-road cycling competitions. Med Sci Sports Exerc 2002;34:1808-13.

2 Stapelfeldt B, Schwirtz A, Schumacher YO, et al. Workload demands in mountain bike racing. Int J Sports Med 2004;25:294-300.

3 Wilber RL, Zawadzki KM, Kearney JT, et al. Physiological profiles of elite offroad and road cyclists. Med Sci Sports Exerc 1997;29:1090-4.

4 Lee H, Martin DT, Anson JM, et al. Physiological characteristics of successful mountain bikers and professional road cyclists. J Sports Sci 2002;20:1001-8.

5 Baron R. Aerobic and anaerobic power characteristics of off-road cyclists. Med Sci Sports Exerc $2001 ; 33: 1387-93$.

6 Impellizzeri FM, Rampinini E, Sassi A, et al. Physiological correlates to offroad cycling performance. J Sports Sci 2005;23:41-7.

7 Atkinson G, Nevill AM. Selected issues in the design and analysis of sport performance research. J Sports Sci 2001;19:811-27.

8 Westgarth-Taylor C, Hawley JA, Rickard S, et al. Metabolic and performance adaptations to interval training in endurance-trained cyclists. Eur J Appl Physiol Occup Physiol 1997;75:298-304

9 Lindsay FH, Hawley JA, Myburgh KH, et al. Improved athletic performance in highly trained cyclists after interval training. Med Sci Sports Exerc 1996;28: 1427-34.

10 Hawley JA, Noakes TD. Peak power output predicts maximal oxygen uptake and performance time in trained cyclists. Eur J Appl Physiol Occup Physiol 1992;65:79-83.

11 Balmer J, Davison RC, Bird SR. Peak power predicts performance power during an outdoor 16.1-km cycling time trial. Med Sci Sports Exerc 2000;32: 1485-90.

12 Lucia A, Hoyos J, Perez $M$, et al. Which laboratory variable is related with time trial performance time in the Tour de France? Br J Sports Med 2004; 38:636-40

13 Takaishi T, Yasuda Y, Moritani T. Neuromuscular fatigue during prolonged pedalling exercise at different pedalling rates. Eur J Appl Physiol Occup Physiol 1994;69:154-8.

14 Kuipers $\mathbf{H}$, Verstappen FT, Keizer HA, et al. Variability of aerobic performance in the laboratory and its physiologic correlates. Int J Sports Med 1985;6:197-201

15 Duncan GE, Howley ET, Johnson BN. Applicability of $\mathrm{VO}_{2}$ max criteria: discontinuous versus continuous protocols. Med Sci Sports Exerc 1997;29:273-8.

16 Gaskill SE, Ruby BC, Walker AJ, et al. Validity and reliability of combining three methods to determine ventilatory threshold. Med Sci Sports Exerc 2001;33:1841-8.

17 Lucia A, Joyos H, Chicharro JL. Physiological response to professional road cycling: climbers vs. time trialists. Int J Sports Med 2000;21:505-12.

18 Lucia A, Pardo J, Durantez A, et al. Physiological differences between professional and elite road cyclists. Int J Sports Med 1998;19:342-8.

19 Amann M, Subudhi AW, Walker J, et al. An evaluation of the predictive validity and reliability of ventilatory threshold. Med Sci Sports Exerc 2004;36:1716-22.

20 Meyer T, Faude O, Scharhag J, et al. Is lactic acidosis a cause of exercise induced hyperventilation at the respiratory compensation point? $\mathrm{Br} J$ Sports Med 2004;38:622-5

21 Boning D, Maassen N, Thomas A, et al. Extracellular pH defense against lactic acid in normoxia and hypoxia before and after a Himalayan expedition. Eur J Appl Physiol 2001:84:78-86.

22 Larsson P, Olofsson P, Jakobsson E, et al. Physiological predictors of performance in cross-country skiing from treadmill tests in male and female subjects. Scand J Med Sci Sports 2002;12:347-53.

23 Eisenman PA, Johnson SC, Bainbridge CN, et al. Applied physiology of crosscountry skiing. Sports Med 1989;8:67-79.

24 Padilla S, Mujika I, Cuesta G, et al. Level ground and uphill cycling ability in professional road cycling. Med Sci Sports Exerc 1999;31:878-85.

25 Kearney JT. Sport performance enhancement: design and analysis of research. Med Sci Sports Exerc 1999;31:755-7. 